\title{
A Neural Network Model for the Compressive Strength of a Hybrid LM6 Aluminium Alloy Composite
}

\author{
Sathyabalan P, Srimath R
}

\begin{abstract}
Adding more than one reinforcement increases the flexibility in composites. The objective of the work is to develop a model to predict the compressive strength in an LM6 aluminium alloy reinforced with $\mathrm{SiC}$ and flyash particles. Central composite rotatable design had been employed to carry out the experiments with size and composition of the reinforcements as the parameters. ANN model developed has good prediction accuracy with error being less than $5 \%$.
\end{abstract}

Keywords-LM6 aluminium alloy, SiC, flyash, Compressive strength, ANN

\section{INTRODUCTION}

Metal matrix composites (MMC) due to their tailorability, have enabled the development of high strength to weight ratio materials possessing improved mechanical and thermal properties over conventional materials [1][2]. Aluminium, abundantly available and having very high strength to weight ratio is the widely used matrix material. $\mathrm{SiC}$ possessing good strength, excellent resistance to wear and corrosion has been the primary material used as reinforcement [3] in composites. Flyash, the waste material has been used primarily as a filler material in paints and polymers. Researchers have incorporated flyash particles in metal alloys to reduce density. They have observed reduced wear, improved modulus in the resulting composites [4].

Composites can be made more amenable to application requirement by adding more than one reinforcement. Various researches have been conducted to study the behavior of hybrid composites [5][6][7][8]. Particle reinforcements exhibit isotropy; possess good stiffness and commendable manufacturability besides being inexpensive [9]. The size of particles [10] impacts the behavior of composites. The properties of composites are influenced by the content of reinforcements [11].

Various techniques have been adopted to model the influence of parameters in physical phenomena. Factorial design of experiments [12] has been applied to predict the behavior of composites. Basavarajappa et al. applied Taguchi techniques [13] to study the dry sliding wear behavior of metal matrix composites. Artificial Neural Network models have been developed to predict the behavior of composite materials under various loads [14][15].

$\mathrm{SiC}$ and flyash particles have been dispersed in LM6, aluminium silicon alloy, a highly corrosion resistant casting alloy. The corrosion resistance of the alloy is very good even in marine environments. An attempt has been made to develop a neural network model for the compressive strength of composite in terms of the size and weight of the reinforcement particles.

\section{Nomenclature \\ $\sigma_{\mathrm{c}}-$ Compressive strength in $\mathrm{MPa}$ \\ $\mathrm{F}_{\mathrm{s}}-$ Flyash size in microns \\ $\mathrm{S}_{\mathrm{s}}-$ SiCsize in microns \\ F - Weight of flyash as \% of LM6 \\ $\mathrm{S}-$ Weight of $\mathrm{SiC}$ as \% of LM6}

\section{EXPERIMENTAL}

Flyash from Raichur power plant, India provided by ACC Cements Coimbatore, India, has been used in the study. The composition of flyash is presented in Table I. The reinforcement particles were sieved in different size ranges. Each of the reinforcement was considered for different size ranges to ensure distinctiveness in their role. The parameter levels were determined from trial runs.The maximum weight was constrained to $10 \%$ to ensure proper synthesizing of composites. The parameters and their limits determined from (1) are presented in Table II.

\section{TABLE I. CHEMICAL COMPOSITION OF FLYASH}

\begin{tabular}{llllllllll}
\hline $\mathrm{SiO}_{2}$ & $\mathrm{Al}_{2} \mathrm{O}_{3}$ & $\mathrm{Fe}_{2} \mathrm{O}_{3} \mathrm{TiO}_{2}$ & $\mathrm{~K}_{2} \mathrm{O}$ & $\mathrm{CaO}$ & $\mathrm{MgO}$ & $\mathrm{Na}_{2} \mathrm{O} \mathrm{SO} \mathrm{SO}_{3}$ & $\mathrm{LI}^{*}$ \\
\hline 62.8 & 28.2 & 4.17 & 1.9 & 0.89 & 0.84 & 0.38 & 0.26 & 0.01 & 0.53 \\
\hline
\end{tabular}

* Loss on ignition

Central composite rotatable design for experimentation with four factors and five levels has been considered in arriving at the combination of parameters. All the star and factorial points of the 31 experiment design have been considered for the network. Only one centre point has been considered to ensure proper training of the network.

$$
Z_{i}=\frac{2\left[2 Z-\left(Z_{\max }-Z_{\min }\right)\right]}{\left(Z_{\max }-Z_{\min }\right)}
$$

Revised Manuscript Received on August 19, 2019.

Sathyabalan P,Department of Mechanical Engineering, Kumaraguru College of Technology, Coimbatore,T.N,India. (E-mail sathyabalan.p.mec@kct.ac.in)

Srimath R, Department of Mechanical Engineering, Sri Ramakrishna Engineering College, Coimbatore,T.N. India. (E-mail: srimath@srec.ac.in) 
TABLE II.LEVELS AND LIMITS OF PARAMETERS

\begin{tabular}{|l|c|c|c|c|c|}
\hline \multirow{2}{*}{\begin{tabular}{l} 
Paramete \\
\cline { 2 - 6 }
\end{tabular}} & \multicolumn{5}{|c|}{ Parameter Levels } \\
\hline $\boldsymbol{F}_{\boldsymbol{s}}$ & $0-40$ & $40-106$ & $\begin{array}{c}106- \\
150\end{array}$ & $\begin{array}{c}150- \\
180\end{array}$ & $\begin{array}{c}180- \\
250\end{array}$ \\
\hline $\boldsymbol{S}_{\boldsymbol{s}}$ & $0-25$ & $25-40$ & $40-63$ & $63-90$ & $\begin{array}{c}90- \\
106\end{array}$ \\
\hline $\boldsymbol{F}$ & 2 & 4 & 6 & 8 & 10 \\
\hline $\boldsymbol{S}$ & 2 & 4 & 6 & 8 & 10 \\
\hline
\end{tabular}

Hybrid composites were fabricated using the cost effective stir casting method [16]. SiC and flyash were heated and dispersed into molten aluminium alloy. Reinforcements are added and stirred when the temperature of the aluminium alloy reached $720^{\circ} \mathrm{C}$. Magnesium has been added to improve wetting of the reinforcements [17]. Molten composite has been solidified in preheated metallic dies. Specimens with the combination of parameters as given by the design process have been cast.

Compression testing had been carried out on $10 \mathrm{~mm}$ square specimens. The responses of the testing along with the combinations of parameters are presented in Table III. The specimens fractured by compression testing are shown in Fig.1.

TABLE III.DESIGN AND RESPONSES

\begin{tabular}{|c|c|c|c|c|c|}
\hline Exp & $\mathbf{F}_{\mathbf{s}}$ & $\mathbf{S}_{\mathbf{s}}$ & $\mathbf{F}$ & $\mathbf{S}$ & $\sigma_{\mathrm{c}}$ \\
\hline 1 & -1 & -1 & -1 & -1 & 386 \\
\hline 2 & +1 & -1 & -1 & -1 & 324 \\
\hline 3 & -1 & +1 & -1 & -1 & 345 \\
\hline 4 & +1 & +1 & -1 & -1 & 335 \\
\hline 5 & -1 & -1 & +1 & -1 & 331 \\
\hline 6 & +1 & -1 & +1 & -1 & 314 \\
\hline 7 & -1 & +1 & +1 & -1 & 319 \\
\hline 8 & +1 & +1 & +1 & -1 & 355 \\
\hline 9 & -1 & -1 & -1 & +1 & 317 \\
\hline 10 & +1 & -1 & -1 & +1 & 306 \\
\hline 11 & -1 & +1 & -1 & +1 & 326 \\
\hline 12 & +1 & +1 & -1 & +1 & 324 \\
\hline 13 & -1 & -1 & +1 & +1 & 329 \\
\hline 14 & +1 & -1 & +1 & +1 & 321 \\
\hline 15 & -1 & +1 & +1 & +1 & 384 \\
\hline 16 & +1 & +1 & +1 & +1 & 367 \\
\hline 17 & -2 & 0 & 0 & 0 & 312 \\
\hline 18 & +2 & 0 & 0 & 0 & 354 \\
\hline 19 & 0 & -2 & 0 & 0 & 327 \\
\hline 20 & 0 & +2 & 0 & 0 & 318 \\
\hline 21 & 0 & 0 & -2 & 0 & 354 \\
\hline 22 & 0 & 0 & +2 & 0 & 339 \\
\hline 23 & 0 & 0 & 0 & -2 & 382 \\
\hline 24 & 0 & 0 & 0 & +2 & 364 \\
\hline 25 & 0 & 0 & 0 & 0 & 366 \\
\hline & & & & \\
\hline
\end{tabular}

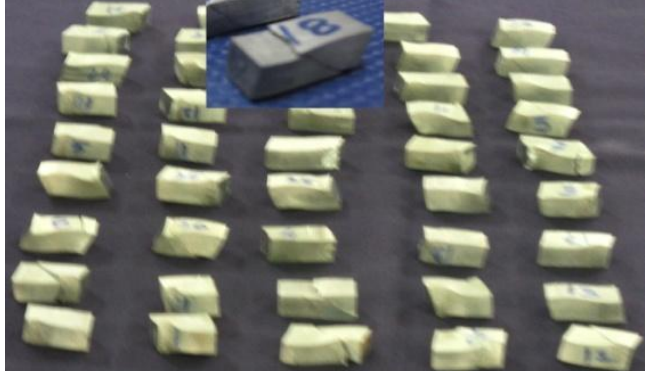

Fig. 1.Compressive fractured specimens

Neural network toolbar of MATLAB has been used in developing the model. Normalization of input and output data from 0.1 to 0.9 to support training and testing has been done using (2). Feedforward back propagation network has been developed, with training being carried out with Levenberg-Marquardt algorithm, providing fastest convergence [18].

$\mathrm{X}_{\mathrm{norm}}=0.1+0.8\left(\frac{\mathrm{X}-\mathrm{X}_{\min }}{\mathrm{X}_{\max }-\mathrm{X}_{\min }}\right)$

where $\mathrm{X}_{\text {norm }}$ - Normalized value

$\mathrm{X}$-Value to be normalized

$\mathrm{X}_{\min }$ - Minimum value

$\mathrm{X}_{\max }-$ Maximum value

\section{RESULTS AND DISCUSSION}

A neural network with 5 neurons in the single hidden layer has been developed to predict the compressive strength of the composite. The very low mean square error value of 0.000218761 indicates very good accuracy of the model.

Simulink toolbar of MATLAB has been enabled to build a model to test the developed neural network. Comparision of actual values with predicted ones for testing and training are presented in the form of scatter plots in Fig. 2 and Fig. 3 respectively. The correlation coefficient $\left(\mathrm{R}^{2}\right)$ during training and testing stages are 0.9991 and 0.9864 respectively. The closeness of values to 1 indicates the integrity of learning and testing [19]. The application of systematic concept of design of experiments has been a key factor in the accuracy of the model.

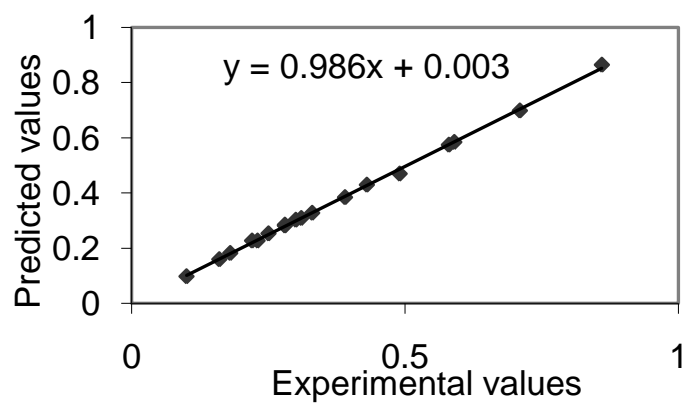

Fig. 2.Scatter plot for the training stage of compressive strength 




Fig. 3.Scatter plot for the training stage of compressive strength

\section{CONCLUSION}

LM6 aluminium alloy composites reinforced with $\mathrm{SiC}$ and flyash have been synthesised using the stir casting. ANN model to predict the compressive strength of the hybrid composite in terms of the content and size of the reinforcements has been developed. The ANN model prediction was accurate with the maximum error in prediction being about $2 \%$ within the selected domain.

\section{ACKNOWLEDGMENT}

The authors acknowledge the financial support and technical facilities provided by Kumaraguru College of Technology, Coimbatore, India.

\section{REFERENCES}

1. Chawla N and Chawla $\mathrm{K} \mathrm{K}$, "Metal-matrix composites in ground transportation", JOM, vol. 58, no.11, pp. 67-70, 2006.

2. V.V. Bhanu Prasad, K.S. Prasad, A.K. Kuruvilla, A.B. Pandey,B.V.R. Bhat and Y.R. Mahajan, "Composite strengthening in 6061 and Al4Mg alloys", Journal of Materials Science, vol. 26, pp. 460-466, 1991.

3. Sahin Y, "Wear behaviour of aluminium alloy and its composites reinforced by $\mathrm{SiC}$ particles using statistical analysis", Materials and Design, vol. 24, pp. 95-103, 2003.

4. Rohatgi PK,Guo RQ, Keshavaram BN and Golden DM, "Cast aluminium, fly ash composites for engineering applications", AFS Transactions, vol. 103, pp. 575-579, 1995.

5. Michael Oluwatosin Bodunrin,Kenneth Kanayo Alaneme and Lesley Heath Chown, "Aluminium Matrix hybrid composites: a review of reinforcement philosophies; mechanical, corrosion and tribological characteristics",JMater ResTechnol ., 4(4): pp.434-445, 2015.

6. Monikandan VV, Joseph MA and Rajendrakumar PK, "Dry sliding wear studies of aluminum matrix hybrid composites" ResourceEfficient Technologies 2, S12-S24, 2106.

7. Velmurugan C, Subramanian R, Thirugnanam S and Anandavel $\mathrm{B}$,"Investigation of friction and wear behavior of hybrid aluminium composites", Industrial Lubrication and Tribology, vol. 64 Issue: 3 , pp.152-163, 2012.

8. Vamsi Krishnaa V and Anthony.M.Xavior, "An Investigation on the Mechanical Properties of Hybrid Metal Matrix Composites", Procedia Engineering, 97,pp.918 - 924, 2014.

9. Huda D, El Baradie MA and Hashmi MSJ, "Metal-matrix composites: Materials aspects. Part II", Journal of Materials Processing Technology, vol. 37, pp. 529-541, 1993.

10. Chai-Yuan and Su-Jien Linh, "Particle size effects on the abrasive wear of $20 \mathrm{vol} \% \mathrm{SiCp} / 7075 \mathrm{Al}$ composites" Scripta Mater., vol. 35,pp. 1271-1276, 1996.

11. Tjong SC, Wu SQ and Liao HC, "Wear behaviour of an Al-12\% Si alloy reinforced with a low volume fraction of $\mathrm{SiC}$ particles", Composites Science and Technology, vol. 57, pp. 1551-1558, 1997.

12. Spuzic S, Zec M, Abhary K, Ghomaschi and Reid I, "Fractional design of experiments applied to a wear simulation", Wear, vol. 212,pp. 131-139, 1997.

13. Basavarajappa S, Chandramohan G and Paulo Davim J, "Application of Taguchi techniques to study dry sliding wear behaviour of metal matrix composites", Short Communication, Materials and Design, vol. 28,Issue 4, pp. 1393-1398, 2007.

14. Zhenyu Jiang, Lada Gyurova, Zhong Zhang, Klaus Friedrich andAlois K. Schlarb," Neural network based prediction on mechanical and wear properties of short fibers reinforced polyamide composites", Materials and Design, vol. 29, pp. 628-637, 2008.

15. Nagaraj, B., and R. Murugananth. "Optimum PID controller tuning using soft computing methodologies for industrial process." J Comput Sci India 4, no. 5 (2010): 1761-1768.

16. H.R. Hafizpour, M. Sanjari and A. Simchi, "Analysis of the effect of reinforcement particles on the compressibility of Al-SiC composite powders using a neural network model", Materials and Design, vol. 30, Issue 5, pp. 1518-1523, 2009.

17. Tee KL, Lu L and Lai MO, "Synthesis of in situ Al-TiB 2 composites using stir cast route", Composite Structures, vol. 47, pp. 589-593, 1999

18. Hashim J, Looney L and Hashmi MSJ, "The enhancement of wettability of $\mathrm{SiC}$ particles in cast aluminium matrix composites Journal of Materials Processing Technology, vol. 119 (1-3), pp. 329335, 2001

19. Rasit Koker, Necat Altinkok and Adem Demir, "Neural network based prediction of mechanical properties of particulate reinforced metal matrix composites using various training algorithms", Materials and Design, vol.28, pp. 616-627, 2007

20. N. Selvakumar, P. Ganesan, P. Radha, R. Narayanasamy andK.S Pandey, "Modelling the effect of particle size and iron content on forming of $\mathrm{Al}-\mathrm{Fe}$ composite preforms using neural network", Materials and Design, vol. 28, pp. 119-130, 2007. 